\title{
The effect of routine hoof trimming on locomotion score, ruminating time, activity, and milk yield of dairy cows
}

\author{
T. Van Hertem, ${ }^{*} \dagger$ Y. Parmet, $\ddagger$ M. Steensels, ${ }^{\star} \dagger$ E. Maltz, ${ }^{*}$ A. Antler, ${ }^{*}$ A. A. Schlageter-Tello,§ C. Lokhorst, $\S$ \\ C. E. B. Romanini, † S. Viazzi, † C. Bahr, $†$ D. Berckmans, $†$ and I. Halachmi ${ }^{* 1}$ \\ *Institute of Agricultural Engineering-Agricultural Research Organization (ARO)—the Volcani Center, PO Box 6, Bet-Dagan IL-50250, Israel \\ †Division M3-BIORES: Measure, Model and Manage Bioresponses, KU Leuven, Kasteelpark Arenberg 30 - bus 2456 , BE-3001 Heverlee, \\ Belgium \\ $\ddagger$ Department of Industrial Engineering and Management, Ben Gurion University of the Negev, PO Box 653, Beer-Sheva IL-10501, Israel \\ §WageningenUR Livestock Research, PO Box 65, NL-8200AB Lelystad, the Netherlands
}

\section{ABSTRACT}

The objective of this study was to quantify the effect of hoof trimming on cow behavior (ruminating time, activity, and locomotion score) and performance (milk yield) over time. Data were gathered from a commercial dairy farm in Israel where routine hoof trimming is done by a trained hoof trimmer twice per year on the entire herd. In total, 288 cows spread over 6 groups with varying production levels were used for the analysis. Cow behavior was measured continuously with a commercial neck activity logger and a ruminating time logger (HR-Tag, SCR Engineers Ltd., Netanya, Israel). Milk yield was recorded during each milking session with a commercial milk flow sensor (Free Flow, SCR Engineers Ltd.). A trained observer assigned on the spot 5-point locomotion scores during 19 nighttime milking occasions between 22 October 2012 and 4 February 2013. Behavioral and performance data were gathered from $1 \mathrm{wk}$ before hoof trimming until $1 \mathrm{wk}$ after hoof trimming. A generalized linear mixed model was used to statistically test all main and interactive effects of hoof trimming, parity, lactation stage, and hoof lesion presence on ruminating time, neck activity, milk yield, and locomotion score. The results on locomotion scores show that the proportional distribution of cows in the different locomotion score classes changes significantly after trimming. The proportion of cows with a locomotion score $\geq 3$ increases from $14 \%$ before to $34 \%$ directly after the hoof trimming. Two months after the trimming, the number of cows with a locomotion score $\geq 3$ reduced to $20 \%$, which was still higher than the baseline values 2 wk before the trimming. The neck activity level was significantly reduced $1 \mathrm{~d}$ after trimming (380 \pm 6 bits/d) compared with before trimming $(389 \pm 6$ bits/d). Each one-unit increase in locomo-

Received October 8, 2013.

Accepted April 16, 2014.

${ }^{1}$ Corresponding author: halachmi@volcani.agri.gov.il tion score reduced cow activity level by 4.488 bits/d. The effect of hoof trimming on ruminating time was affected by an interaction effect with parity. The effect of hoof trimming on locomotion scores was affected by an interaction effect with lactation stage and tended to be affected by interaction effects with hoof lesion presence, indicating that cows with a lesion reacted different to the trimming than cows without a lesion did. The results show that the routine hoof trimming affected dairy cow behavior and performance in this farm.

Key words: hoof trimming, locomotion score, ruminating time, neck activity, milk yield

\section{INTRODUCTION}

Lameness is defined as an alteration in gait and posture resulting from pain or discomfort in the legs and hoofs of the animal (Flower and Weary, 2009). In dairy farms with cubicle housing and concrete floors, foot disorders can be a major welfare problem with serious economic consequences (Bruijnis et al., 2012). The average lameness prevalence is around $28 \%$ in Austria (Kofler et al., 2013), 28.5\% in Canada (Ito et al., 2010), 33.2\% in Chili (Tadich et al., 2010), 36.8\% in England and Wales (Barker et al., 2010), 46.4\% in the United States (Cramer et al., 2008), and 34\% in Germany (Dippel et al., 2009). Some of the key factors that are associated with lameness are housing (Frankena et al., 2009; Bicalho and Oikonomou, 2013; Chapinal et al., 2013), nutrition (Dippel et al., 2009), lying surface (Dippel et al., 2009; Bicalho and Oikonomou, 2013), breed (Barker et al., 2010), and herd size (Cramer et al., 2009b). However, key risk factors vary across regions or countries (Chapinal et al., 2013), and a successful prevention measure in one herd may be a risk in another herd if not carried out properly (Cramer et al., 2009b).

Lameness can cause a reduction in milk yield (Onyiro et al., 2008; Reader et al., 2011), a change animal 
behavior responses (Chapinal et al., 2010; Ito et al., 2010; Van Hertem et al., 2013), and a delay in the reproduction cycle (Hultgren et al., 2004; Walker et al., 2010). Furthermore, lameness alters the resting behavior of cows during transition, and it was associated with an elevated risk for ketosis (Calderon and Cook, 2011). Lameness increases the culling risk of the animal (Booth et al., 2004; Cramer et al., 2009a). The economic consequences of lameness and hoof disorders are estimated to be on average 53 Euro per cow per year (Bruijnis et al., 2013b), of which indirect costs are the main part. Subclinical foot disorders account for $32 \%$ of the total costs (Bruijnis et al., 2010).

Different lameness prevention strategies and treatment protocols are documented in literature (Potterton et al., 2012; Relun et al., 2013). The biggest problem might be that farmers have a low awareness for the lameness problem in their herd (Sarova et al., 2011; Bruijnis et al., 2013a). Foot bathing (Holzhauer et al., 2012), washing (Thomsen et al., 2012), and disinfection of hooves (Thomsen et al., 2008) are important in the prevention and treatment of infectious lameness but not noninfectious lameness. Hoof trimming is suggested to be important for controlling lameness (Manske et al., 2002; Hernandez et al., 2007; Bryan et al., 2012); even for infectious lameness like digital dermatitis, additional foot trimming can be effective (Bruijnis et al., 2013b).

Different hoof-trimming techniques are documented, and all techniques led to an improvement of the pressure distribution pattern in the hoofs (Zeiner et al., 2007). Hoof trimming is commonly used because it improves the balance between the medial and lateral claw (Bryan et al., 2012), and it increases the weight-bearing contact area of the claws or targets the highest pressures to the strongest parts of the claw capsule (van der Tol et al., 2004). However, the trimmer has an individual influence on hoof shape and balance (Kummer et al., 2009) and the recording of specific hoof lesions (Cramer et al., 2009b). Literature has found positive and negative results of hoof trimming. Claw trimming and associated handling cause stress reactions in cattle (Pesenhofer et al., 2006). Pesenhofer et al. (2006) showed that claw trimming in a tilt table was less stressful than the mobile walk-in crush. Cows that received one-time hoof trimming increased their milk fat and milk protein compositions after trimming (Nishimori et al., 2006). Both lame and nonlame cows increased their lying time after hoof trimming, and daily lying time remained higher for up to 5 wk after hoof trimming (Chapinal et al., 2010). Walking characteristics such as walking rate, step length, and stepping rate improved after hoof trimming (Aoki et al., 2006). The short-term effect of trimming claw horn lesions on locomotion, activity, and milk yield was described by Montgomery et al. (2012).
In the study of Montgomery et al. (2012), only the noninfectious lame cow response to trimming was studied. In addition to that, the short-term effect of trimming on ruminating time was not quantified before. Our hypothesis was (1) that trimming affected the behavior and performance of the cows and (2) that this effect was not related to the parity or lactation stage of the cows. Therefore, the aim of this study was to quantify the effect of preventive hoof trimming on lame (infectious and noninfectious cases) and nonlame cows with regard to locomotion score, ruminating time, activity level, and milk yield.

\section{MATERIALS AND METHODS}

\section{Animals and Housing}

The experiments were conducted by the Agricultural Research Organization in Refet HaEmek, a commercial dairy farm in kibbutz Yifat, Israel. The milking herd comprised 1,100 Israeli-Holstein cows. Mean parity in the herd was $2.6 \pm 1.6$ lactations, with an annual replacement rate of $33 \%$. The annual milk production was $11,500 \mathrm{~kg} /$ cow. The herd was divided in 12 production groups according to parity, lactation stage, reproduction status, and health status (group size: $96 \pm 12$ cows). All cows were housed all-year round in separate no-stall, fully roofed, open cowsheds with dried-manure bedding material. Stocking rate was on average 19.3 $\mathrm{m}^{2} /$ cow in each production group. Lameness prevalence ranged between 15 and $25 \%$ throughout the year.

All cows were milked 3 times a day (start at 0300, 1100, and $1900 \mathrm{~h}$ ) in a $2 \times 32$ side-by-side milking parlor. The production groups were brought one-by-one to the waiting parlor to avoid group mixing. First, the cows in early lactation were milked, then the primiparous groups, followed by the multiparous cows, and at last the sick cows.

Each cowshed had a post and rail feed fence on one side of the barn, and a 3-m-wide area near this feeding lane was paved in concrete. All lactating cows were fed a TMR according to NRC recommendations (NRC, 2001) appropriate to their stage of lactation, age, and level of production. Trucks from the local feeding center delivered the TMR twice daily (around 0600 and $1100 \mathrm{~h}$ ). The feed was offered to the cows ad libitum and pushed to the cows at least 6 times daily. Water was freely available at all times in the cowsheds and waiting parlor.

\section{Hoof Trimming}

Normal hoof-care management on the farm is that all (lactating and dry) cows receive routine hoof trim- 
ming twice a year, before summer and before winter. In the experimental data collection period, a routine hoof trimming on the entire herd (approximately 1,100 cows) was conducted from 19 November until 29 November. All cows were trimmed by 2 trained claw trimmers. One claw trimmer trimmed the hind hooves, and the other trimmed the front hooves. Trimmer effect was not part of the study. The cows were fixated in a tilt table for claw trimming. The tilt table was tilted from a vertical to a horizontal position, laying the cows on their right flank. The trimming procedure comprised 5 steps:

1. trim toe length,

2. dish out a slight hollow with a scraper,

3. cut hoof edges with hoof clippers,

4. smooth edges of claw with electric grinding disk, and

5. treat and disinfect hoof disorders (such as sole ulcer, double sole) and claw skin diseases (such as digital dermatitis and dermatitis interdigitalis).

Steps 4 and 5 were only executed when the trimmer found it appropriate. The trimmer listed all identified lesions and hoof diseases and reported the list to the farmer.

\section{Locomotion Scoring}

The cows were locomotion scored during the night milking session (between 2100 and $0130 \mathrm{~h}$ ) on 19 different occasions between 22 October 2012 and 4 February 2013 (Figure 1). During each locomotion scoring session, cows were on-the-spot manually locomotion scored by a trained observer using the discrete 5 -point numerical score $(1=$ healthy; $5=$ severely lame) of Sprecher et al. (1997; later on referred to as locomotion score or LS). The observer was standing after a sorting gate in the exit lane of the milking parlor. All cows came one by one through this sorting gate and continued their walk back to the pen in a straight line through a grooved concrete-floored corridor. The observer faced all passing cows in flank view perspective from a 6 -m distance.

The intraobserver repeatability of the trained observer for the 5-point score was quantified as suggested by Cohen (1960) and achieved a percentage of agreement of $67.9 \pm 1.2 \%$, a kappa coefficient of $53.3 \pm 2.4 \%$, and a weighed kappa coefficient of $68.8 \pm 2.9 \%$ in 4 consecutive locomotion scoring sessions. These values indicate moderate to substantial repeatability (Landis and Koch, 1977).

Because not all cows were trimmed on the same day, the number of scores before and after trimming differed for each cow. Therefore the 19 different scoring occa- sions were transformed to 6 occasions by calculating the average locomotion score of occasions that were close to each other in function of time. This resulted in 3 occasions before $\left(\mathbf{d}_{-34}\right.$ : $34 \pm 2 \mathrm{~d}$ before trimming; $\mathbf{d}_{-18}: 18 \pm 2 \mathrm{~d}$ before trimming; $\mathbf{d}_{-4}: 4 \pm 1 \mathrm{~d}$ before trimming) and 3 occasions after $\left(\mathbf{d}_{+2}: 2 \pm 1 \mathrm{~d}\right.$ after trimming; $\mathbf{d}_{+15}: 15 \pm 1 \mathrm{~d}$ after trimming; $\mathbf{d}_{+70}: 70 \pm 2$ $\mathrm{d}$ after trimming) the hoof-trimming event.

\section{Behavior and Performance Sensors}

The milking parlor was equipped with an electronic milk-yield meter (FreeFlow, SCR Engineers Ltd., Netanya, Israel) at every individual stand. This gave a milk yield measurement expressed in kilograms during each milking. Milk production was expressed as kilograms milk per day, so 3 consecutive measurements were summed. All cows in the farm were equipped with a neck collar tag (HR-Tag, SCR Engineers Ltd.) used for automated heat detection (Bar, 2010; Kamphuis et al., 2012). The tag had 3 functions: (i) cow identification based on optical signal transmission; (ii) real-time individual neck activity level measurement; and (iii) real-time individual ruminating time measurement. Activity measurement was based on the signal analysis of the head movements and was expressed by a filtered activity index ranging from 0 to 255 bits for a 2 -h interval. The activity index was proportional to the number, intensity (amplitude), and direction of the neck movements. The daily activity level was calculated as the mean of the available daily measurements, multiplied by 12 . The rumination logger continuously recorded the time spent ruminating within a $24-\mathrm{h}$ period in 2-h intervals, as was validated by Schirmann et al. (2009). Ruminating time was expressed as minutes of ruminating per $2 \mathrm{~h}$. The daily rumination level was calculated as the mean of the available daily measurements, multiplied by 12 . If within a day more than 3 data points were missing, the day was discarded from the data set.

All data were transferred automatically during each milking to the herd management software (DataFlow, SCR Engineers Ltd.). Reports were extracted from this software in a spreadsheet format (Microsoft Excel, Microsoft Corp., Redmond, WA).

\section{Database Building}

Daily data were gathered during a 4 -mo period (November 2012-February 2013). Only 6 production groups (around 560 cows; the last to be milked) were followed. Cow parity and lactation stage (DIM) were extracted from the management software. Parity values were categorized to 3 categories: parity 2, parity 3 , and parity 


\section{Day relative to day of trimming}

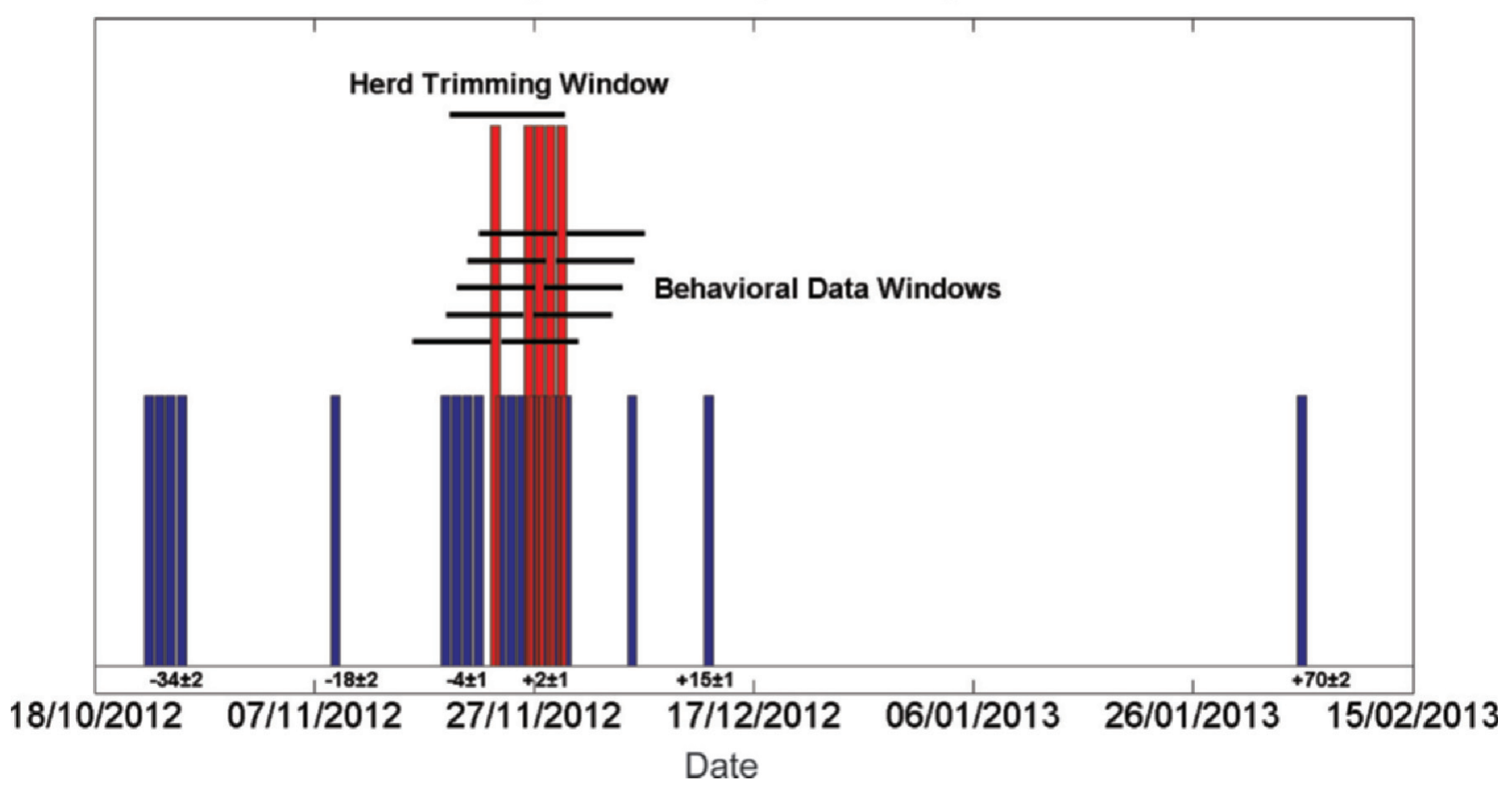

Figure 1. Detailed overview of the timing of the locomotion scoring occasions. In total, 19 live locomotion scoring sessions (short vertical bars) during nighttime milking (from 2100 until $0130 \mathrm{~h}$ ) were performed between 22 October 2012 and 4 February 2013. All cows were trimmed during the herd-trimming window. Behavior and performance were studied in the week before and after trimming (black horizontal lines). Because of the different trimming occasions of the groups (represented by the tall bars), the behavioral and performance data windows did not start at the same time. Color version available in the online PDF.

$\geq 4$. First-parity cows were omitted from the analysis. Cows from the sick pen were omitted from the analysis because their behavior and performance data are biased by their sickness. Lactation stage was categorized to 4 categories to reduce the degrees of freedom in the statistical analysis: early $=\mathrm{DIM} \leq 100 ;$ mid $=100<$ $\mathrm{DIM} \leq 200 ;$ late $=200<\mathrm{DIM} \leq 300 ;$ and over $1 \mathrm{yr}$ $=\mathrm{DIM}>300$. The presence of lesions as scored by the hoof trimmer was included in the database as binary data (yes/no). A total of 408 cows were locomotion scored both in the week before and after hoof trimming. A subset of 152 cows was locomotion scored on all 6 occasions spread over the 4 mo around hoof trimming (3 before; 3 after). In another subset of 288 cows, be- havioral and performance data were recorded in both the week before and after hoof trimming. Table 1 shows the descriptive statistics of the 288 cows.

\section{Statistical Analysis}

For analysis, data were standardized to the date of trimming (d 0 ). The subset of 152 cows with 6 repetitions of locomotion scores was used to test the longterm effect of trimming on the proportion of locomotion scores and lameness prevalence (LS $\geq 3$ ) in the herd. Significant differences between the 6 time points were found with a multiple comparison of the Friedman test (Friedman, 1937), which is based on the column rank

Table 1. Descriptive statistics of 288 cows with behavioral and performance data ${ }^{1}$

\begin{tabular}{llcccc}
\hline Variable & Unit & Mean & SD & Minimum & Maximum \\
\hline Parity & Lactations & 3.2 & 1.5 & 2 & 9 \\
DIM & $\mathrm{d}$ & 259 & 166 & 27 & 994 \\
Activity & bits/d & 390 & 75 & 168 & 735 \\
Rumination & min/d & 468 & 83 & 176 & 651 \\
Milk & $\mathrm{kg} / \mathrm{d}$ & 35.3 & 10.4 & 10.2 & 63.3 \\
\hline
\end{tabular}

${ }^{1}$ For each variable, the mean, standard deviation, minimum, and maximum values in the data set are given. 
differences between the time points (Matlab R2011b, the MathWorks Inc., Natick, MA).

The subset of 408 cows with locomotion scores in the week before and after trimming was used to test the short-term effect of trimming on the proportion of locomotion scores and lameness prevalence (LS $\geq 3$ ) in the herd. For each cow, the average locomotion score value in the week before trimming and after trimming was calculated. A paired $t$-test was used to test the significance between before and after trimming.

To quantify the short-term effect, behavioral and performance data of 288 cows of 1 wk before and after trimming were used. These 288 cows had at least one locomotion score before and after the trimming event that were taken into account. The effect of hoof trimming on the 4 measured variables (daily ruminating time, daily neck activity level, daily milk yield, and daily locomotion score) was statistically tested with a generalized linear mixed model (GLMM) using IBM SPSS Statistics 21.0 (International Business Machines Corp., Armonk, NY). Time was considered to be a repeated measure. The behavior and performance data on the week before trimming, the day of trimming, the day after trimming, the $3 \mathrm{~d}$ after trimming, and 4 to $7 \mathrm{~d}$ after hoof trimming are represented by the average value of the variables in these time periods. Daily milk-yield recordings smaller than $1 \mathrm{~L}$, rumination recordings less than $100 \mathrm{~min} / \mathrm{d}$, and activity recordings less than 50 bits or more than 1,000 bits/d were considered as false sensor recordings, and they were together with estrus days filtered out before the analysis by treating them as missing values. The 288 complete cow-observations were used for the analysis. Cow parity, lactation stage, lesion presence, and time were treated as fixed factors. To account for repeated measures taken on each cow and production group, cow and group were included as random effects in the GLMM analysis. All predictorvariables main effects and 2-way interaction terms with time were included for statistical-model development.

\section{RESULTS}

\section{Locomotion Scores Around Hoof Trimming}

Figure 2 shows the proportion of cows in the 5 locomotion scoring classes in function of time during 6 scoring sessions around hoof trimming ( 3 before; 3 after). In each of the 6 time points, the mean locomotion score of several days around this time point was calculated. Because of dry off, culling, and group changes, only 152 individual cows were included in all 6 time points.

Before the hoof-trimming period, the proportion of cows scored as LS $=1$ was $51 \%$ on $\mathrm{d}_{-34}$, changed to $54 \%$ on $\mathrm{d}_{-18}$, and became $41 \%$ immediately before trimming $\left(\mathrm{d}_{-4}\right)$. Immediately after trimming, this proportion decreased to $22 \%$ and slowly increased to $30 \%$ during the 2 following weeks. Two months after hoof trimming, the proportion of cows with LS $=1$ increased to $40 \%$. The proportion of $\mathrm{LS}=2$ cows started at $34 \%$ on $\mathrm{d}_{-34}$, changed to $31 \%$ on $\mathrm{d}_{-18}$, and became $43 \% 4 \pm 1 \mathrm{~d}$ before trimming. The highest proportion of LS $=2$ was obtained $2 \pm 1 \mathrm{~d}$ after trimming (45\%). This level decreased to $38 \% 15 \pm 1 \mathrm{~d}$ after trimming and to $39 \% 70$ $\pm 2 \mathrm{~d}$ after trimming. The proportion of LS $=3$ started at $10 \%$ on $\mathrm{d}_{-34}$, changed to $12 \%$ immediately before trimming, and increased even further to $26 \%$ when all cows were trimmed. This level decreased slightly to $22 \%$ in the following $2 \mathrm{wk}$ and decreased to $16 \%$ after 2 mo. The proportion of cows in the group LS $=4$ was stable around $4 \%$ before trimming but increased to $6 \%$ and eventually $10 \% 17 \mathrm{~d}$ after hoof trimming. Two months after hoof trimming, the proportion of cows in $\mathrm{LS}=4$ reduced to $5 \%$. The proportion of cows in the group LS $=5$ ranged throughout the period between 0 and $2 \%$, with the highest proportion immediately after the hoof-trimming period.

Lameness prevalence (LS $\geq 3$ ) went from over $15 \%$ to $16 \%$ before trimming. Immediately after the hooftrimming period, lameness prevalence increased to $33 \%$. Lameness prevalence slightly decreased to $32 \% 17$ $\mathrm{d}$ after trimming. Two months after the hoof-trimming period, lameness prevalence was $21 \%$, still higher than before the hoof-trimming period.

The letters a, b, and c in Figure 2 denote the significantly different locomotion scoring distributions between the 6 different time points. Significance was tested with the Friedman test. The 2 locomotion scoring sessions at $2 \pm 1$ and $15 \pm 1 \mathrm{~d}$ after trimming were statistically identical ( $95 \% \mathrm{CI}=-0.45$ to 0.45$)$. Both the locomotion scoring sessions at $\mathrm{d} 2 \pm 1$ and $15 \pm 1$ after trimming differed significantly from the session 34 $\pm 2 \mathrm{~d}$ before trimming $(-1.69$ to -0.78$)$, from the session $18 \pm 2 \mathrm{~d}$ before trimming $(-1.72$ to -0.82$)$, from the session $4 \pm 1 \mathrm{~d}$ before trimming $(-1.38$ to -0.47$)$, and from the session at $70 \pm 2 \mathrm{~d}$ after trimming ( 0.14 to 1.05). The locomotion scoring session at $70 \pm 2 \mathrm{~d}$ after trimming differed from the locomotion scoring session $34 \pm 2 \mathrm{~d}$ before trimming ( -1.09 to -0.18$)$ as well as from the session at $18 \pm 2 \mathrm{~d}$ before trimming $(-1.13$ to -0.22$)$, but no significant difference between the locomotion scoring sessions at $4 \pm 1 \mathrm{~d}$ before trimming and $70 \pm 2 \mathrm{~d}$ after trimming ( -0.79 to 0.12 ) was found. All 3 locomotion scoring sessions before trimming were found to be not significantly different from each other.

Figure 3 shows a stacked bar graph of the proportion of cows in each locomotion score class around hoof trimming. In total 408 individual cows are presented in both bar graphs. Lameness prevalence (LS $\geq 3$ ) in- 


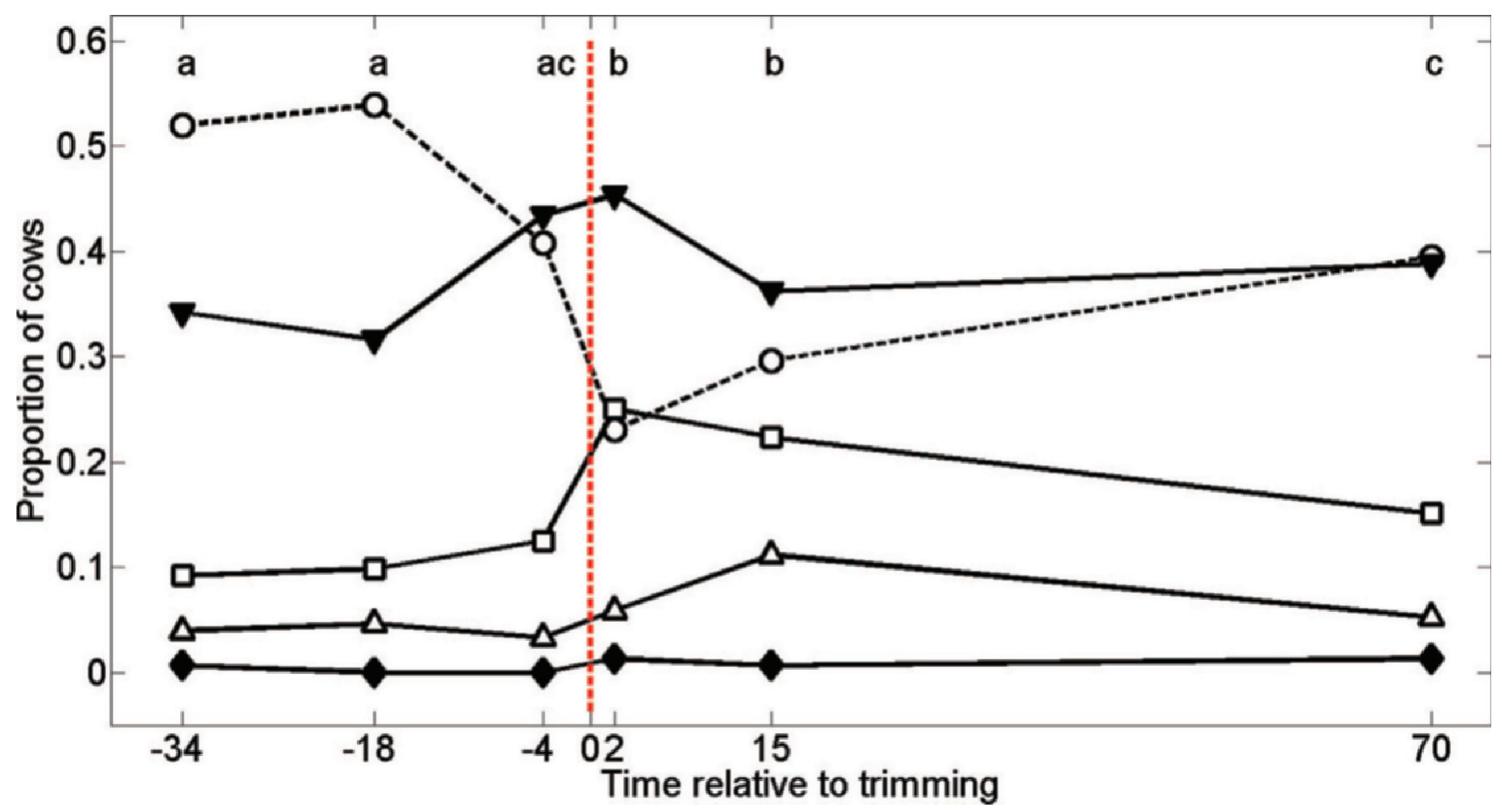

Figure 2. Proportion of cows distributed into the 5 locomotion score classes (LS =1: ○; LS $=2: \boldsymbol{\nabla} ; \mathrm{LS}=3: \square ; \mathrm{LS}=4: \Delta ; \mathrm{LS}=5: \diamond$ ). All cow data were standardized relative to the day of hoof trimming (d 0: vertical dashed line). Nineteen live locomotion scoring sessions conducted between 22 October 2012 and 4 February 2013 are transformed into 6 points in time that are included in the graph $(-34 \pm 2 \mathrm{~d} ;-18 \pm 2 \mathrm{~d} ;-4$ $\pm 1 \mathrm{~d} ; 2 \pm 1 \mathrm{~d} ; 15 \pm 1 \mathrm{~d} ; 70 \pm 2 \mathrm{~d}$ ). This transformation is done by calculating the mean locomotion score during several consecutive locomotion scoring sessions around these 6 points in time. In each time point, 152 cows were included. Friedman's statistical test was used to test whether locomotion score distributions in the 6 time points were equal. Significant differences are denoted with the different letters a, b, and c. Color version available in the online $\mathrm{PDF}$.

creased significantly from $27 \%$ before trimming to $41 \%$ after trimming.

\section{GLMM}

The Effect of Hoof Trimming on Locomotion Scores. The GLMM (Table 2) revealed that the main effect of hoof trimming on the locomotion score of cows was significant $(P=0.034)$. More specifically, locomotion score was lowest before the trimming [2.285 \pm 0.126 units; Table 3(a)]. The highest locomotion scores were reached in the first $3 \mathrm{~d}$ after the trimming $(2.702$ \pm 0.132 units). Furthermore, the trimming effect was dependent on lactation stage $(P=0.028)$ and tended to depend on the presence of lesions $(P=0.063)$, and milk yield $(P=0.084)$. Locomotion score was also affected by parity $(P<0.001)$, the presence of lesions $(P$ $<0.001)$, activity level $(P=0.021)$, and ruminating time $(P=0.025)$. Cows identified with a lesion $[2.791$ \pm 0.139 units; Table 3(b)] had higher locomotion scores than cows without a lesion (2.280 \pm 0.132 units). Each 1-bit increase in daily activity level resulted in a 0.276 decrease in locomotion score (Table 4). Each one-unit increase in daily ruminating time resulted in a 0.228 decrease in locomotion score (Table 4).

The Effect of Hoof Trimming on Ruminating Time. The GLMM (Table 2) revealed that the effect of hoof trimming on ruminating time for nonlame cows was dependent on the parity of the cow $[F(8,1026)=$ 4.645; $P<0.001]$. The ruminating time of the cows was dependent on the milk yield $[F(1,1026)=35.571$; $P<0.001]$ and tended to depend on the locomotion score $[F(1,1026)=3.751 ; P=0.053]$ and the activity level of the cows $[F(1,1026)=3.335 ; P=0.068]$. Each $1-\mathrm{kg}$ increase in daily milk yield resulted in a $21.9-\mathrm{min} / \mathrm{d}$ increase in daily ruminating time (Table 4). Each 1-bit increase in daily activity level tended to decrease the daily ruminating time by $9.8 \mathrm{~min} / \mathrm{d}$ (Table 4). Each one-unit increase in locomotion score tended to decrease the daily ruminating time by $6.2 \mathrm{~min} / \mathrm{d}$ (Table 4).

The Effect of Hoof Trimming on Neck Activity. The GLMM (Table 2) revealed that hoof trimming had a significant effect on neck activity for dairy cows $(P=0.036)$. More specifically, Table 5 shows that neck activity level was highest at the day of the trimming 


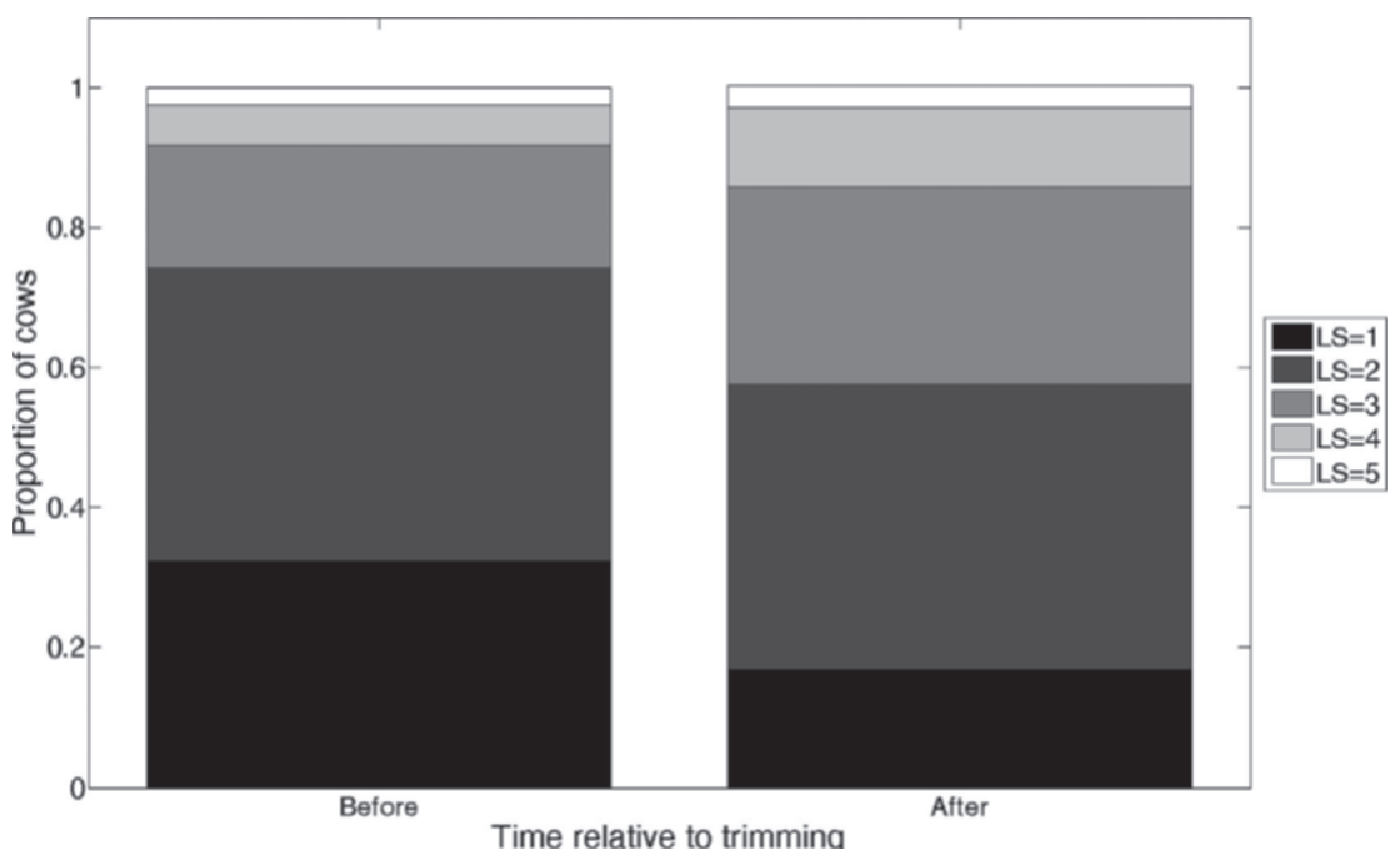

Figure 3. Proportion distribution of cows in the 5 different locomotion score (LS) classes before $(\mathrm{d}-5)$ and after $(\mathrm{d}+5)$ trimming. LS $=5$, white; $\mathrm{LS}=4$, light gray; $\mathrm{LS}=3$, medium gray; $\mathrm{LS}=2$, dark gray; $\mathrm{LS}=1$, black. In total, 408 cows were included in the analysis.

$(400.9 \pm 5.7 \mathrm{bits} / \mathrm{d})$. Activity level was lower one day after trimming $(380.1 \pm 6.2 \mathrm{bits} / \mathrm{d})$ than before the trimming $(389.3 \pm 5.6 \mathrm{bits} / \mathrm{d})$. Furthermore, the trimming effect was dependent on cow parity $(P=0.024)$ and the presence of lesions $(P=0.009)$ and tended to depend on the milk yield $(P=0.061)$. Neck activity level was also affected by parity $(P<0.001)$, ruminating time $(P=0.007)$, milk yield $(P<0.001)$, and locomotion score $(P=0.038)$. Each 1-min increase in daily ruminating time decreased the daily activity level

Table 2. Overview of the 4 general linear mixed models (GLMM) with the different source input variables and 1 of the 4 output variables (activity, rumination, milk, and locomotion) ${ }^{1}$

\begin{tabular}{|c|c|c|c|c|c|c|c|c|c|c|}
\hline Source & df1 & df2 & \multicolumn{8}{|c|}{ Output variable } \\
\hline Lesion & 1 & 1,026 & 22.031 & $<0.001$ & 0.144 & 0.70 & 2.226 & 0.14 & 0.090 & 0.76 \\
\hline Parity & 2 & 1,026 & 11.643 & $<0.001$ & 0.265 & 0.77 & 12.014 & $<0.001$ & 1.334 & 0.26 \\
\hline $\mathrm{DIM}^{2}$ & 3 & 1,026 & 0.178 & 0.91 & 0.753 & 0.52 & 0.356 & 0.78 & 58.448 & $<0.001$ \\
\hline Rumination & 1 & 1,026 & 5.009 & 0.025 & NA & NA & 7.240 & 0.007 & 44.395 & $<0.001$ \\
\hline Activity & 1 & 1,026 & 5.375 & 0.021 & 3.335 & 0.068 & NA & NA & 9.577 & 0.002 \\
\hline Milk & 1 & 1,026 & 0.547 & 0.46 & 35.571 & $<0.001$ & 12.305 & $<0.001$ & NA & NA \\
\hline Time $\times$ lesion & 4 & 1,026 & 2.236 & 0.063 & 1.138 & 0.34 & 3.415 & 0.009 & 0.266 & 0.90 \\
\hline Time $\times$ parity & 8 & 1,026 & 0.984 & 0.45 & 4.645 & $<0.001$ & 2.217 & 0.024 & 1.828 & 0.068 \\
\hline Time $\times$ DIM & 12 & 1,026 & 1.926 & 0.028 & 0.864 & 0.58 & 0.714 & 0.74 & 1.662 & 0.070 \\
\hline Time $\times$ locomotion & 4 & 1,026 & NA & NA & 0.331 & 0.86 & 1.230 & 0.30 & 1.313 & 0.26 \\
\hline
\end{tabular}

${ }^{1}$ The degrees of freedom for the model (df1 and df2) and the $F$-statistic are given in the table, together with the significance level of the source variable in the resulting GLMM.

${ }^{2}$ DIM refers to the lactation stage of the cow.

${ }^{3}$ Time refers to the effect of trimming (before trimming vs. after trimming).

${ }^{4} \mathrm{NA}=$ not applicable. 
Table 3. General linear mixed model pairwise comparison of the outcome variable locomotion in relation to the input variables time and lesion ${ }^{1}$

\begin{tabular}{lccccc}
\hline & \multicolumn{5}{c}{ Locomotion } \\
\cline { 2 - 5 } Source & Mean & SD & Lower limit & Upper limit & Significance \\
\hline (a) Time & & & & \\
Before & 2.285 & 0.126 & 2.038 & 2.533 & $\mathrm{~A}$ \\
Trimming day & 2.517 & 0.126 & 2.269 & 2.766 & $\mathrm{~B}$ \\
1 d after & 2.684 & 0.133 & 2.423 & 2.945 & $\mathrm{C}$ \\
1-3 d after & 2.702 & 0.132 & 2.442 & 2.961 & $\mathrm{~B}$ \\
4-7 d after & 2.489 & 0.129 & 2.235 & 2.742 & $\mathrm{~A}$ \\
(b) Lesion & & & & 2.539 & $\mathrm{~B}$ \\
Without lesions & 2.280 & 0.132 & 2.020 & 3.064 & \\
With lesions & 2.791 & 0.139 & 2.518 &
\end{tabular}

${ }^{1}$ The mean, standard deviation, and lower and upper $95 \%$ confidence limits of the locomotion score values are given. The letters A, B, and $\mathrm{C}$ denote the significant difference in locomotion score according to the different timing around trimming. Significance was tested against $\alpha=0.05$.

by $5.8 \mathrm{bits} / \mathrm{d}$ (Table 4). Each 1-kg increase in daily milk yield increased the daily activity level by $7.2 \mathrm{bits} / \mathrm{d}$ (Table 4). Each one-unit increase in locomotion score decreased the daily activity level by $4.5 \mathrm{bits} / \mathrm{d}$ (Table 4).

The Effect of Hoof Trimming on Milk Yield. The GLMM (Table 2) revealed that the effect of hoof trimming on milk yield for dairy cows tended to depend on the parity of the cows $[F(8,1026)=1.828 ; P$ $=0.068]$ and lactation stage $[F(12,1026)=1.662 ; P=$ 0.070]. The milk yield was also affected by the lactation stage $[F(3,1026)=58.448 ; P<0.001]$, activity level $[F(1.1026)=9.577 ; P=0.002]$, and ruminating time $[F(1,1026)=44.395 ; P<0.001]$. Each 1 -min increase in daily ruminating time increased the milk yield by $3.1 \mathrm{~kg} / \mathrm{d}$ (Table 4). Each 1-bit increase in daily activity level increased the milk yield by $0.9 \mathrm{~kg} / \mathrm{d}$ (Table 4 ).

\section{DISCUSSION}

The results suggest that hoof trimming affects both locomotion scores and dairy-cow behavior. After the hoof-trimming process, the proportion of cows in lo- comotion score class 1 decreased significantly. This indicates that nonlame cows increased their locomotion score after trimming, suggesting that hoof trimming caused discomfort or even pain, which resulted in an alteration of the gait. Another possibility is that the alteration in gait could be due to the fact that hoof trimming changed hoof conformation, and that cow needed to adjust for balance. In general, all cows increased their locomotion score after trimming, because time did have an effect on locomotion score [Table 3(a)]. The interaction effect between lesion presence and time around trimming revealed that cows with a lesion had a different reaction to the trimming than cows without a lesion [Table 3(b)]. Blackie et al. (2013) found in their study that gait alterations were more evident in cows with sole ulcers.

Chapinal et al. (2010) found a 5-wk effect of trimming on the daily lying time of dairy cows. In this study, the trimming had a lasting effect of at least 10 wk on the locomotion-score distribution of the cows. The activity, ruminating-time, and milk-yield data, measured by the sensors used in this farm, seemed to have returned to their baseline values by 1 wk after

Table 4. General linear mixed model (GLMM) coefficients of the 4 different GLMM with varying output variables

\begin{tabular}{llcccc}
\hline & & \multicolumn{3}{c}{ Output } \\
\cline { 3 - 5 } Input & Unit & Activity & Rumination & Milk & Locomotion \\
\hline Activity & bits/d & $\mathrm{NA}^{2}$ & -9.8 & 0.9 & -0.3 \\
Rumination & $\mathrm{min} / \mathrm{d}$ & -5.8 & $\mathrm{NA}$ & 3.1 & -0.2 \\
Milk & $\mathrm{kg} / \mathrm{d}$ & 7.2 & 21.9 & $\mathrm{NA}$ & $\mathrm{NS}^{3}$ \\
Locomotion & units & -4.5 & -6.2 & $\mathrm{NS}$ & $\mathrm{NA}$ \\
\hline${ }^{1}$ The coefficients represent the resulting increase (when coefficient is positive) or decrease (when coefficient is \\
negative) in output (columns) for each one unit increase in input (rows). Only the coefficients of the measured \\
behavioral and performance variables that were significant at $\alpha=0.05$ are provided. \\
${ }^{2} \mathrm{NA}=$ not applicable. \\
${ }^{3} \mathrm{NS}=$ not significant at $\alpha=0.05$.
\end{tabular}


Table 5. Tabular overview of the effect of trimming (time) on the daily activity level of dairy cows ${ }^{1}$

\begin{tabular}{lccccc}
\hline & \multicolumn{5}{c}{ Activity (bits/d) } \\
\cline { 2 - 5 } Source & Mean & SD & Lower limit & Upper limit & Significance \\
\hline Time & & & & & \\
Before & 389.3 & 5.6 & 378.2 & 400.3 & $\mathrm{C}$ \\
Trimming day & 400.9 & 5.7 & 389.8 & 412.1 & $\mathrm{~A}$ \\
1 d after & 380.1 & 6.2 & 368.0 & 392.3 & $\mathrm{~B}$ \\
1-3 d after & 384.8 & 6.2 & 372.7 & 396.9 & BC \\
4-7 d after & 383.5 & 5.9 & 372.0 & 395.1 & BC
\end{tabular}

${ }^{1}$ The mean, standard deviation, and lower and upper $95 \%$ confidence limits of the activity level (unit: bits/d) are given. The significant differences in daily activity level according to the different time around trimming are denoted by the letters A, B, and C. Significance was tested against $\alpha=0.05$.

trimming, as was found by Montgomery et al. (2012). This might indicate that these sensors on their selves are not specific enough for lameness detection.

Five days before the trimming event, the number of cows with $\mathrm{LS}=1$ tended to decrease, whereas the number of cows with $\mathrm{LS}=2$ tended to increase. Not all cows were trimmed on the exact same day. The fact that not all cows were trimmed on the exact same day might lead to speculations due to the day-to-day variations in weather and the subjectivity of the expert scorer for the changing trend before trimming. In general, the only parameter that has been changed was the trimming of the cows in the herd. Mild illnesses were not considered in the analysis. If the cow got a severe illness, the procedure in this farm was to move the cow to the sick pen, and all cows from the sick pen were eliminated from the analysis in this study. Statistical analysis of the locomotion score distributions over time revealed that the scores sessions before trimming were not significantly different.

On the day of the trimming, cow behavior was deviant from other days. Neck-activity level and locomotion score increased, whereas ruminating time and milk yield decreased on this day. On this day, the cows were brought as a group to the waiting area before trimming. This extra walk to the waiting area and the waiting for their turn to be trimmed may explain the increase in activity level of the cows. Only when all cows were trimmed, the group was brought back to the pen. This implies that the cows were taken out of their routine; they were deprived from food and rest for several hours. The decrease in ruminating time might be due to this food deprivation. Deprivation from food combined with hoof trimming resulted in the study of Cooper et al. (2008) in a reduced milk yield in the next $3 \mathrm{~d}$, whereas the results in this study did not show a reduced milk yield in the days after the trimming. Parity and lactation stage had an interaction effect.

First-parity cows were omitted from the analysis because the main production groups with first-parity cows were not included in the experiment. The few included first-parity cows would not have been a correct representation of the first-parity cow population. Parity had a strong interaction effect with hoof trimming on neck activity and ruminating time and a weak interaction effect on milk yield (Table 2). The effect of trimming on the behavior and performance variables differed for the different parity groups. In general, the trimming had less effect on older-cow behavior and performance. Many fixed factors influence animal behavior and performance in relation to lameness (Huang et al., 1995). The interactions were different for each behavior or performance variable (Table 2).

Only 6 of the 12 production groups in the farm were followed in time during this data-gathering process. The groups were chosen before the experiment. Six groups near the end of the milking process (but not the last group) were chosen because these groups consisted of older cows, and lameness prevalence was higher in these groups compared with the other excluded groups. Also for practical reasons during the live locomotion scoring sessions, it was preferred to follow consecutive groups and not more than 500 cows in order not to compromise the scorer's reliability. Therefore, the cows in this analysis were not a representative sample of the entire herd as the groups were selected. The distribution of the cows in the groups was based on management practices: cows were grouped based on parity, milking speed, health status, and lactation stage. Therefore, the factor group was not used in the analysis as a fixed factor but as a random factor because the cow-specific characteristics were uniformly distributed within and not across all groups.

The results show that hoof trimming had a large effect on the neck-activity level and locomotion score of the cows, and the trimming indirectly affected the milk yield and ruminating time of the cows. Although the primary commercial use of activity sensing is heat detection, studies have shown a relation between activity and lameness as well. The method of activity measurement might differ, because literature describes neck activity (Van Hertem et al., 2013) and pedometer activity 
(Miekley et al., 2013). To our knowledge, no study ever described whether pedometer activity is a better or more reliable indicator for cow gait than neck activity. Locomotion score and activity are related to cow gait and posture, whereas milk yield and ruminating time are not, and therefore a larger effect of trimming on these variables was expected. A first remark might be that the effect on milk yield and ruminating time is not accountable to the trimming itself but to the deprivation of food and rest, which are indirectly related to the trimming process, and the stress associated with the trimming event. It is also possible that the cows ate fewer meals per day but instead ate greater portions in one meal. Hence, the daily feed intake did not change although the feeding behavior might have changed. Another remark is that this study only examined shortterm effects. It might be that the effect of trimming on the long term might improve activity level, locomotion score, and milk yield. A final remark is that although milk yield was tested on a short-term, a small decline in daily milk yield after peak lactation is natural in the normal lactation curve (persistency).

This study showed that a routine hoof trimming affects dairy-cow behavior. Before executing a preventive hoof trimming on the entire herd, the farmer should take these effects into consideration. It may be better to select only the lame cows for trimming and leave the nonlame cows untouched. It is also important to perform a correct trimming practice. Relun et al. (2013) described that because of a lack of available guidelines, farmers often misuse treatments and the expected effectiveness of the treatment is not obtained. Also Huang et al. (1995) question the routine hoof-trimming practices because they emphasize that cows trimmed more frequently usually had a higher probability of repeating their problems. The economic cost of misused treatments could be investigated in further research.

The exact recovery time from the hoof trimming and the specific effect of different lesion types were not quantified in this analysis. Although the locomotion scores peaked in the $3 \mathrm{~d}$ after the trimming, neck-activity level seemed to recover to its initial values before the trimming on the second or third day after the trimming. Pavlenko et al. (2011) showed in their study that cows with digital dermatitis had a stronger behavioral response to the claw disease than cows affected with sole ulcers. Further research should reveal how long the effect of hoof trimming persists on animal behavior and how the type of lesion affects the recovery time in this farm.

The results show that on this farm the hoof trimming affected cow behavior. The study was limited to the data of one farm, which may not have been a representative subsample of the entire (Israeli) dairy herd. Furthermore, the fact that data were taken from one team of experienced hoof trimmers and one routine hoof trimming in November is a limitation and makes it impossible to extrapolate season or effect of year, both related to the environmental conditions in the farm. Another issue might be that although the data have statistical differences, the biological meaning behind these differences is not always well understood or differentiated from simple anomalies. In this study, the activity level ranged between 380 and 400 bits/d (Table 5). This is a range of $20 \mathrm{bits} / \mathrm{d}$, or $5 \%$, which seems to be more than an anomaly. Therefore, it is advised to take caution when extrapolating these results to all farms. Nevertheless, the correct use of management practices to control lameness such as the timing of a hoof-trimming event should be integrated in the decision-making process to develop integrated decision-support models (Rutten et al., 2013) or automated welfare-assessment schemes (Rushen et al., 2012).

\section{CONCLUSIONS}

The distribution of locomotion scores on group level changes significantly after routine hoof trimming. The trimming has a lasting effect on locomotion scores up to $70 \mathrm{~d}$ after the event. Daily neck-activity level decreased by $4 \mathrm{bits} / \mathrm{d}$ for every one-unit increase in locomotion score. Neck activity was significantly increased on the day of the trimming ( $401 \pm 6$ bits/d) but was significantly decreased $1 \mathrm{~d}$ after the trimming (380 \pm 6 bits/d) compared with the neck activity level before trimming $(389 \pm 6$ bits/d). The effects of hoof trimming on ruminating time and milk yield were relatively small and depended on the interaction with fixed factors such as parity and lactation stage. Increased locomotion score or lameness affected neck-activity level and ruminating time of the cows. Routine hoof trimming affected cow behavior and performance depending on cow parity, lactation stage, and the presence of lesions.

\section{ACKNOWLEDGMENTS}

The authors thank all farm personnel for their help on the farm. This study is part of the Marie Curie Initial Training Network BioBusiness (FP7-PEOPLEITN-2008). This study is contribution number 459-4398951, funded by the Agricultural Research Organization (ARO), PO Box 6, Bet Dagan, Israel.

\section{REFERENCES}

Aoki, Y., M. Kamo, H. Kawamoto, J. Zhang, and A. Yamada. 2006. Changes in walking parameters of milking cows after hoof trimming. Anim. Sci. J. 77:103-109. 
Bar, D. 2010. Optimal timing of insemination using activity collars. Pages 100-101 in First North Am. Conf. Precision Dairy Manag., Toronto, Canada. Sentex, Cambridge, ON, Canada.

Barker, Z. E., K. A. Leach, H. R. Whay, N. J. Bell, and D. C. J. Main. 2010. Assessment of lameness prevalence and associated risk factors in dairy herds in England and Wales. J. Dairy Sci. 93:932-941.

Bicalho, R. C., and G. Oikonomou. 2013. Control and prevention of lameness associated with claw lesions in dairy cows. Livest. Sci. 156:96-105.

Blackie, N., E. C. L. Bleach, J. R. Amory, and J. R. Scaife. 2013. Associations between locomotion score and kinematic measures in dairy cows with varying hoof lesion types. J. Dairy Sci. 96:3564-3572.

Booth, C. J., L. D. Warnick, Y. T. Grohn, D. O. Maizon, C. L. Guard, and D. Janssen. 2004. Effect of lameness on culling in dairy cows. J. Dairy Sci. 87:4115-4122.

Bruijnis, M., H. Hogeveen, C. Garforth, and E. Stassen. 2013a. Dairy farmers' attitudes and intentions towards improving dairy cow foot health. Livest. Sci. 155:103-113.

Bruijnis, M. R. N., B. Beerda, H. Hogeveen, and E. N. Stassen. 2012. Foot disorders in dairy cattle: Impact on cow and dairy farmer. Anim. Welf. 21:33-40.

Bruijnis, M. R. N., H. Hogeveen, and E. N. Stassen. 2010. Assessing economic consequences of foot disorders in dairy cattle using a dynamic stochastic simulation model. J. Dairy Sci. 93:2419-2432.

Bruijnis, M. R. N., H. Hogeveen, and E. N. Stassen. 2013b. Measures to improve dairy cow foot health: Consequences for farmer income and dairy cow welfare. Animal 7:167-175.

Bryan, M., H. Tacoma, and F. Hoekstra. 2012. The effect of hindclaw height differential and subsequent trimming on lameness in large dairy cattle herds in Canterbury, New Zealand. N. Z. Vet. J. 60:349-355.

Calderon, D. F., and N. B. Cook. 2011. The effect of lameness on the resting behavior and metabolic status of dairy cattle during the transition period in a freestall-housed dairy herd. J. Dairy Sci. 94:2883-2894.

Chapinal, N., A. K. Barrientos, M. A. G. von Keyserlingk, E. Galo, and D. M. Weary. 2013. Herd-level factors for lameness in freestall farms in the northeastern United States and California. J. Dairy Sci. 96:318-328.

Chapinal, N., A. M. De Passille, and J. Rushen. 2010. Correlated changes in behavioral indicators of lameness in dairy cows following hoof trimming. J. Dairy Sci. 93:5758-5763.

Cohen, J. 1960. A coefficient of agreement for nominal scales. Educ. Psychol. Meas. 20:37-46.

Cooper, M. D., D. R. Arney, and C. J. C. Phillips. 2008. The effect of temporary deprivation of lying and feeding on the behaviour and production of lactating dairy cows. Animal 2:275-283.

Cramer, G., K. D. Lissemore, C. L. Guard, K. E. Leslie, and D. F. Kelton. 2008. Herd- and cow-level prevalence of foot lesions in Ontario dairy cattle. J. Dairy Sci. 91:3888-3895.

Cramer, G., K. D. Lissemore, C. L. Guard, K. E. Leslie, and D. F. Kelton. 2009a. The association between foot lesions and culling risk in Ontario Holstein cows. J. Dairy Sci. 92:2572-2579.

Cramer, G., K. D. Lissemore, C. L. Guard, K. E. Leslie, and D. F. Kelton. 2009b. Herd-level risk factors for seven different foot lesions in Ontario Holstein cattle housed in tie stalls or free stalls. J. Dairy Sci. 92:1404-1411.

Dippel, S., M. Dolezal, C. Brenninkmeyer, J. Brinkmann, S. March, U. Knierim, and C. Winckler. 2009. Risk factors for lameness in freestall-housed dairy cows across two breeds, farming systems, and countries. J. Dairy Sci. 92:5476-5486.

Flower, F. C., and D. M. Weary. 2009. Gait assessment in dairy cattle. Animal 3:87-95.

Frankena, K., J. G. C. J. Somers, W. G. P. Schouten, J. V. van Stek, J. H. M. Metz, E. N. Stassen, and E. A. M. Graat. 2009. The effect of digital lesions and floor type on locomotion score in Dutch dairy cows. Prev. Vet. Med. 88:150-157.

Friedman, M. 1937. The use of ranks to avoid the assumption of normality implicit in the analysis of variance. J. Am. Stat. Assoc. 32:675-701.
Hernandez, J. A., E. J. Garbarino, J. K. Shearer, C. A. Risco, and W. W. Thatcher. 2007. Evaluation of the efficacy of prophylactic hoof health examination and trimming during midlactation in reducing the incidence of lameness during late lactation in dairy cows. J. Am. Vet. Med. Assoc. 230:89-93.

Holzhauer, M., C. J. Bartels, C. Bergsten, M. M. J. van Riet, K. Frankena, and T. J. G. M. Lam. 2012. The effect of an acidified, ionized copper sulphate solution on digital dermatitis in dairy cows. Vet. J. 193:659-663.

Huang, Y. C., R. D. Shanks, and G. C. McCoy. 1995. Evaluation of fixed factors affecting hoof health. Livest. Prod. Sci. 44:115-124.

Hultgren, J., T. Manske, and C. Bergsten. 2004. Associations of sole ulcer at claw trimming with reproductive performance, udder health, milk yield, and culling in Swedish dairy cattle. Prev. Vet. Med. 62:233-251.

Ito, K., M. A. G. von Keyserlingk, S. J. LeBlanc, and D. M. Weary. 2010. Lying behavior as an indicator of lameness in dairy cows. J. Dairy Sci. 93:3553-3560.

Kamphuis, C., B. delaRue, C. R. Burke, and J. Jago. 2012. Field evaluation of 2 collar-mounted activity meters for detecting cows in estrus on a large pasture-grazed dairy farm. J. Dairy Sci. 95:3045-3056

Kofler, J., G. Pesenhofer, G. Landl, I. Sommerfeld-Stur, and C. Peham. 2013. Monitoring of dairy cow claw health status in 15 herds using the computerised documentation program Claw Manager and digital parameters. Tieraerztl. Prax. Ausg. G Grosstiere Nutztiere 41:31-44.

Kummer, M., D. Gygax, C. Lischer, and J. Auer. 2009. Comparison of the trimming procedure of six different farriers by quantitative evaluation of hoof radiographs. Vet. J. 179:401-406.

Landis, J. R., and G. G. Koch. 1977. The measurement of observer agreement for categorical data. Biometrics 33:159-174.

Manske, T., J. Hultgren, and C. Bergsten. 2002. The effect of claw trimming on the hoof health of Swedish dairy cattle. Prev. Vet. Med. 54:113-129.

Miekley, B., E. Stamer, I. Traulsen, and J. Krieter. 2013. Implementation of multivariate cumulative sum control charts in mastitis and lameness monitoring. J. Dairy Sci. 96:5723-5733.

Montgomery, J. A., K. Forgan, C. Hayhurst, E. Rees, J. S. Duncan, J. Gossellein, C. Harding, and R. D. Murray. 2012. Short term effect of treating claw horn lesions in dairy cattle on their locomotion, activity and milk yield. Vet. Sci. Dev. 2:25-30.

Nishimori, K., K. Okada, K. Ikuta, O. Aoki, T. Sakai, and J. Yasuda. 2006. The effects of one-time hoof trimming on blood biochemical composition, milk yield, and milk composition in dairy cows. J. Vet. Med. Sci. 68:267-270.

NRC. 2001. Nutrient Requirements of Dairy Cattle. Vol. 1. 7 ed. Natl. Acad. Press, Washington, DC.

Onyiro, O. M., J. Offer, and S. Brotherstone. 2008. Risk factors and milk yield losses associated with lameness in Holstein-Friesian dairy cattle. Animal 2:1230-1237.

Pavlenko, A., C. Bergsten, I. Ekesbo, T. Kaart, A. Aland, and L. Lidfors. 2011. Influence of digital dermatitis and sole ulcer on dairy cow behaviour and milk production. Animal 5:1259-1269.

Pesenhofer, G., R. Palme, R. M. Pesenhofer, and J. Kofler. 2006. Comparison of two methods of fixation during functional claw trimming - walk-in crush versus tilt table - in dairy cows using faecal cortisol metabolite concentrations and daily milk yield as parameters. Wien. Tierarztl. Monatsschr. 93:288-294.

Potterton, S. L., N. J. Bell, H. R. Whay, E. A. Berry, O. C. D. Atkinson, R. S. Dean, D. C. J. Main, and J. N. Huxley. 2012. A descriptive review of the peer and non-peer reviewed literature on the treatment and prevention of foot lameness in cattle published between 2000 and 2011. Vet. J. 193:612-616.

Reader, J. D., M. J. Green, J. Kaler, S. A. Mason, and L. E. Green. 2011. Effect of mobility score on milk yield and activity in dairy cattle. J. Dairy Sci. 94:5045-5052.

Relun, A., R. Guatteo, M. M. Auzanneau, and N. Bareille. 2013. Farmers' practices, motivators and barriers for adoption of treatments of digital dermatitis in dairy farms. Animal 7:1542-1550. 
Rushen, J., N. Chapinal, and A. M. de Passille. 2012. Automated monitoring of behaviour-based animal welfare indicators. Anim. Welf. 21:339-350.

Rutten, C. J., A. G. J. Velthuis, W. Steeneveld, and H. Hogeveen. 2013. IR: Sensors to support health management on dairy farms. J. Dairy Sci. 96:1928-1952.

Sarova, R., I. Stehulova, P. Kratinova, P. Firla, and M. Spinka. 2011. Farm managers underestimate lameness prevalence in Czech dairy herds. Anim. Welf. 20:201-204.

Schirmann, K., M. A. G. von Keyserlingk, D. M. Weary, D. M. Veira, and W. Heuweiser. 2009. Technical note: Validation of a system for monitoring rumination in dairy cows. J. Dairy Sci. 92:6052-6055.

Sprecher, D. J., D. E. Hostetler, and J. B. Kaneene. 1997. A lameness scoring system that uses posture and gait to predict dairy cattle reproductive performance. Theriogenology 47:1179-1187.

Tadich, N., E. Flor, and L. Green. 2010. Associations between hoof lesions and locomotion score in 1098 unsound dairy cows. Vet. J. $184: 60-65$.

Thomsen, P. T., A. K. Ersboll, and A. C. Sorensen. 2012. Short communication: Automatic washing of hooves can help control digital dermatitis in dairy cows. J. Dairy Sci. 95:7195-7199.
Thomsen, P. T., J. T. Sorensen, and A. K. Ersboll. 2008. Evaluation of three commercial hoof-care products used in footbaths in Danish dairy herds. J. Dairy Sci. 91:1361-1365.

van der Tol, P. P. J., S. S. van der Beek, J. H. M. Metz, E. N. Noordhuizen-Stassen, W. Back, C. R. Braam, and W. A. Weijs. 2004. The effect of preventive trimming on weight bearing and force balance on the claws of dairy cattle. J. Dairy Sci. 87:1732-1738.

Van Hertem, T., E. Maltz, A. Antler, A. Schlageter Tello, C. Lokhorst, C. E. B. Romanini, S. Viazzi, C. Bahr, D. Berckmans, and I. Halachmi. 2013. Lameness detection based on multivariate continuous sensing of milk yield, rumination and neck activity. J. Dairy Sci. 96:4286-4298.

Walker, S. L., R. F. Smith, D. N. Jones, J. E. Routly, M. J. Morris, and H. Dobson. 2010. The effect of a chronic stressor, lameness, on detailed sexual behaviour and hormonal profiles in milk and plasma of dairy cattle. Reprod. Domest. Anim. 45:109-117.

Zeiner, H., H. Schobesberger, M. Skalicky, and C. Stanke. 2007. Effect of different claw trimming methods on the pressure distribution under the bovine claw-An in vitro study. Berl. Munch. Tierarztl. Wochenschr. 120:165-172. 